\title{
A PRÁTICA PEDAGÓGICA DE PROFESSORES DE EDUCAÇÃO FÍSICA FRENTE À INCLUSÃO ESCOLAR
}

DOI 105902/0102830812521

Data de submissão: 09/01/2014 Data de Aceite: 04/11/2014

\author{
Victor Julierme Santos da Conceição \\ Universidade do Extremo Sul Catarinense \\ victorjulierme@yahoo.com.br \\ Bruna Coelho Vassoler \\ Universidade do Extremo Sul Catarinense \\ Jéssica Serafim Frasson \\ Universidade do Extremo Sul Catarinense \\ jehfrasson@hotmail.com
}

RESUMO: Este estudo objetivou compreender como os professores de Educação Física rede pública e particular organizam a sua prática pedagógica para as turmas com alunos com deficiência incluídos. Participaram da pesquisa dois professores e duas professoras de Educação Física das séries finais do ensino fundamental, que lecionam nas turmas em escola da rede estadual e particular do município de Forquilhinha-SC. A coleta de dados se deu através de questionário com perguntas abertas. Nas análises, aprendemos que o pouco envolvimento na formação continuada nas escolas, e a organização do sistema de amparo docente à inclusão escolar é o ponto que mais influencia na prática pedagógica dos professores.

Palavras-chave: Inclusão. Formação de professores. Prática pedagógica. 


\section{Palavras Iniciais: Inclusão Escolar, Formação de Professores e Prática Pedagógica}

O processo de inclusão escolar tem como pressuposto a mobilização da sociedade para um novo olhar frente às diferenças humanas, elegendo-as como um valor a ser assumido por todos, partindo do princípio de que a principal característica do ser humano é a pluralidade, e não a igualdade ou a uniformidade.

Existem inúmeras e contraditórias formas de pensar e de agir, no que diz respeito à inclusão no ambiente escolar, ao espaço onde ocorre a inclusão e aos sujeitos aos quais se referem. A inclusão envolve um processo de reforma e de reestruturação das escolas como um todo, com o objetivo de que todos os alunos possam ter acesso a todas as oportunidades educacionais e sociais oferecidas pela escola.

Conforme a Declaração de Salamanca (1994), o princípio fundamental das escolas inclusivas consiste em todos os alunos aprenderem juntos, sempre que possível, independentemente das dificuldades e das diferenças que apresentam. Essas escolas devem reconhecer e satisfazer as necessidades diversas dos seus alunos, adaptando-se aos vários estilos e ritmos de aprendizagem, de modo a garantir um bom nível de educação para todos.

Mittler (2003) observa que a inclusão diz respeito a todos os alunos, e não somente a alguns. Faz parte da inclusão, criar um ambiente onde todos os estudantes possam desfrutar o acesso e o sucesso no currículo e tornarem-se membros da comunidade escolar e social.

Mantoan; Pieto e Arantes (2006, p. 44), ressaltam sobre a ação metodológica em relação à inclusão que:

As escolas que reconhecem e valorizam as diferenças têm projetos inclusivos de educação. O ensino que ministram diferem radicalmente do proposto para atender às especificidades dos educando que não conseguem acompanhar seus colegas de turma, por problemas que vão desde as deficiências até dificuldades de natureza relacional, motivacional ou cultural dos alunos.

Partindo da perspectiva, que os contextos de ensino-aprendizagem são compostos por uma grande diversidade e que cada aluno possui seu capital cultural, entendemos que estes possuem distintas formas de aprender e progredir. Neste sentido, Mantoan; Pieto e Arantes (2006) ressaltam que cada aluno possui seu tempo de aprendizagem, e que é de fundamental importância que os professores confiem em seus alunos gerando expectativas em relação as progressões de cada um. 
Assim, é de suma importância que os métodos de ensino e aprendizagem sejam diversificados, que os cursos de formação docente sejam realmente aproveitados pelos futuros professores, que possam enriquecer seus conhecimentos sobre o tema da inclusão, que o espaço da escola seja acolhedor e que os conceitos sobre a inclusão sejam repensados e transformados pela sociedade.

Segundo Carreiro da Costa (1994) a formação inicial é aquela correspondente ao período inicial de formação profissional, onde o professor adquire conhecimentos científicos pedagógicos e as competências necessárias para dar conta da carreira docente.

Para Shigunov e Shigunov Neto (2001), é fundamental durante a formação inicial que o acadêmico tenha contato com a realidade escolar através dos estágios para amenizar o impacto, pois quando for exercer efetivamente a docência algumas situações já foram vivenciadas. Isto é muito importante, pois esse contato promove a possibilidade de construir atitudes, ações e reflexões sobre o projeto político-pedagógico da escola, onde irá ou estará atuando. Entretanto, para isso é necessário que os currículos universitários apresentem disciplinas que contemplem a inserção do indivíduo nessa realidade. Desta forma, o futuro professor saberá lidar com situações reais, assumindo a responsabilidade que a carreira exige.

O estágio é o eixo central nos cursos de formação de professores e apresentam os aspectos indispensáveis à construção do ser profissional docente no que se refere à construção da identidade, dos saberes e das posturas necessárias (PIMENTA; LIMA, 2004, p.29).

Compreendemos que é nos estágios curriculares que os acadêmicos possuem um primeiro contato com a realidade escolar. Mas é essencial que este não seja considerado apenas como o momento de práticas do curso, mas sim, como um momento de inserção na cultura escolar, onde os futuros professores possam vivencias momentos conflitantes e gratificantes da prática docente. Assim, tendo em vista as singularidades de cada sujeito, é compreensível que nem todos tenham a mesma profundidade de reflexão acerca das experiências adquiridas nos estágios, assim como a própria formação inicial. Neste sentido, nos embasamos em Nóvoa (1995), onde entendemos que a formação acontece através da reflexividade da prática docente.

“[...] A formação não se constrói por acumulação (de cursos, de conhecimentos ou de técnicas), mas sim através de um trabalho de reflexividade crítica sobre as 
práticas e de (re) construção permanente de uma identidade pessoal (NÓVOA, 1995 p. 25)".

Buscamos em Freire (1987) subsídios para tratar sobre o que para nós conceitua e baliza o ato de reflexão sobre a prática educativa, "a práxis, é a reflexão e ação dos homens sobre o mundo para transformá-lo [...] (p.21)." O autor ainda afirma que a educação exerce um papel fundamental no processo de construção pessoal, que exige uma busca permanente, que só existe no ato responsável de quem a faz (FEIRE, 2002).

Assim, percebemos que a formação permanente auxilia os professores no processo reflexivo para compreender as suas práticas educativas, tomando assim atitudes importantes para a melhoria de sua prática pedagógica. Assim, o seu desenvolvimento profissional acontece por intermédio das atividades que ele cria e reformula, dentre outras formas que o professor tem de executar.

O professor reflexivo nunca se satisfaz com a sua prática, jamais a julga perfeita, concluída, sem possibilidades de aprimoramento. Está sempre em contato com outros profissionais, lê, observa, analisa para atender sempre melhor ao aluno, sujeito e objeto de sua ação docente.

Como professor devo saber que sem a curiosidade que me move, que me inquieta, que me insere na busca, não aprendo nem ensino. Exercer a minha curiosidade de forma correta é um direito que tenho como agente e que corresponde ao dever de lutar por ele, o direito a curiosidade (FREIRE, 2002, p.95).

Dorneles et al. (2012, p.179) ao abordar sobre a postura reflexiva do professor apresentam que:

[...]ao tomar consciência de suas ações, o professor passa a julgá-las e aprimorálas. Nesta dinâmica de construção e reconstrução do saber-fazer, os professores exercitam a ação reflexão-ação, incorporando uma nova cultura de compreensão sobre o que ensinar, por que ensinar, como ensinar e como avaliar o processo ensino-aprendizagem.

Entendemos então que o professor diante de uma postura reflexiva toma conhecimento de sua prática pedagógica, aprimorando as suas metodologias, compreendendo o que ensinar para seus alunos diante de tais situações que enfrenta no seu dia-a-dia. Fazendo com que o professor entenda realmente o sentido de estar ali ensinando, trabalhando tal conteúdo para suas turmas. 
Desta forma, baseando-nos nestas premissas, surgiu o problema de investigação: como os professores de Educação Física organizam a sua prática pedagógica para as turmas com alunos com deficiência incluídos?

Assim, no sentido de responder ao problema de pesquisa este estudo objetivou compreender como os professores de Educação Física rede pública e particular organizam a sua prática pedagógica para as turmas com alunos com deficiência incluídos.

\section{Metodologia}

Este estudo descritivo se dá pela abordagem qualitativa, por se entender que as relações entre a realidade e o sujeito não podem ser traduzidas em números. Para Negrine (2004) a base analógica deste tipo de investigação está centrada na descrição, análise e interpretação das informações recolhidas durante o processo investigatório, procurando entendê-las de forma contextualizada.

Participaram, como colaboradoras da pesquisa, quatro professores de Educação Física, a escolha destes colaboradores se deu afim de que os que aceitassem responder ao questionário e estivessem dispostos a colaborar com a pesquisa, sendo esses professores das séries finais do ensino fundamental da rede estadual e particular do município de Forquilhinha (SC).

Utilizamos como instrumento de coleta de dados um questionário com perguntas abertas, construída a partir dos objetivos da pesquisa. Para a realização da investigação, entramos em contato com as escolas para solicitar o ingresso e contato com os professores de Educação Física. Com a autorização da direção, buscamos os professores que atuavam com as séries finais do ensino fundamental. A direção da escola encaminhou o nome desses professores e mediou a conversa com os mesmos.

Depois dessa primeira aproximação com o campo de investigação, perguntamos se estariam dispostos a participar da pesquisa e explicamos todo o processo de como iria funcionar a coleta das informações. Após o aceite dos professores, passamos a agendar os horários com cada um dos para realizar os questionários. Com os instrumentos em mãos, organizamos a tabulação e sistematização dos dados. Para isso, construímos unidades de significados que deram origem as categorias de análise. 
Os nomes dos professores colaboradores foram alterados por nomes fictícios para manter a identidade dos colaboradores e os aspectos éticos da pesquisa. Para melhor compreensão do estudo apresentamos um breve perfil dos professores colaboradores.

A Professora Joana do ensino público é casada, tem 45 anos, formada em Licenciatura Plena em Educação Física na Universidade do Extremo Sul Catarinense (UNESC), com 22 anos de atuação. Em 1989 realizou um Curso de Pós-Graduação em Ensino da Educação Física.

O Professor João, regente no ensino privado, é solteiro, tem 31 anos, formado em 2008 em Licenciatura e Bacharelado Educação Física (UNESC), possui 8 anos de experiência de magistério e também desenvolve projetos voltados a escolinha de futsal.

A Professora Maria atua no ensino privado e é solteira, tem 27 anos, é formada em 2008 em Licenciatura em Educação Física e terminando o Bacharelado em Educação Física na UNESC. É Pós-Graduada em Educação Física, Fisiologia e Interdisciplinaridade. Atualmente trabalha como professora de Educação Física no ensino fundamental I e II, no período matutino e no período vespertino e noturno trabalha em um clube com administração desportiva.

O Professor Pedro do ensino público é solteiro, tem 37 anos, possui 3 anos de magistério, em 2010 terminou a Licenciatura em Educação Física (UNESC). É Pós-Graduado em Interdisciplinaridade na Educação Física. Atualmente trabalha como professor de Educação Física nas séries finais do ensino fundamental no período matutino e vespertino e no período noturno com turmas do $1^{\circ}$ ao $3^{\circ}$ anos do ensino médio cobrindo a licença prêmio de uma das professoras efetivas da escola.

\section{Categorias de Análise}

Com o objetivo de organizar as informações coletadas através dos colaboradores desta pesquisa, no que diz respeito às teorias apresentadas no referencial teórico, foram construídas duas categorias de análises: 'pareceres sobre a inclusão escolar' e 'prática pedagógica do professor de Educação Física para dar conta da inclusão escolar'. A partir dessas categorias trabalhamos as informações coletadas nos questionários aplicados com os colaboradores professores de Educação Física. A apresentação das categorias de 
análises procura atingir o objetivo do estudo buscando esclarecer as dúvidas em relação ao assunto pesquisado.

\section{Pareceres sobre a Inclusão Escolar}

Nesta categoria discutiremos a compreensão e o conhecimento dos professores com relação à inclusão e a importância dos alunos deficientes nas aulas de Educação Física. Segundo os docentes eles dão muita importância a esses alunos, pois contribui e muito para as suas aulas e com os outros alunos para o trabalho coletivo, para a questão da superação e reconhecimento como seres humanos capaz de enfrentar a sociedade onde vive.

Para Voivodic (2004) o termo inclusão, do verbo incluir, significa compreender, fazer parte de, ou participar. Participação é uma necessidade fundamental do ser humano, e o homem só terá possibilidade de total desenvolvimento numa sociedade que permita e facilite sua participação. Portanto, para que os professores possam fazer a inclusão acontecer eles precisam da colaboração de toda comunidade escolar, dos pais e do poder público, podendo assim desenvolver um trabalho com muito sucesso e satisfatório para todos.

Os professores Pedro e João afirmam a superação dos alunos com relação ao aprendizado em suas aulas, os docentes percebem em suas aulas a interação destes alunos com a turma e com as atividades propostas.

"Percebo que os alunos de inclusão" são muito mais participativos do que podemos imaginar. Acompanho um aluno que sofreu paralisia cerebral por causa de uma meningite na infância. O garoto é espetacular, pois tem muitas dificuldades psicomotoras e mesmo assim desempenha as atividades impostas nas aulas de Educação Física com uma força de vontade que o faz ser 'destaque' positivo perante a turma. Sendo assim, os próprios alunos o tomam como referência para pensar que ele, mesmo com suas limitações é esforçado e comprometido" (Prof. João).

"A principal importância é pelo fato de a Educação Física possibilitar os alunos com deficiências se descobrirem como individuo, como ser integrante da sociedade. De o

\footnotetext{
${ }^{1}$ Termo utilizado para identificar o estudante com deficiência incluído na turma comum de ensino.
} 
professor possibilitar esse aluno a realizar atividades que ele (aluno) talvez nunca fosse realizar em outras disciplinas" (Prof. Pedro).

Baseado nas falas de ambos os professores, entendemos que a inclusão dos alunos com deficiência, em suas aulas, é entendido como incentivo e que os mesmos tenham vontade de estar dentro do contexto social onde vivem. Os alunos compreendem que cada obstáculo de sua vida seja um degrau que irá superar, sendo assim, as aulas de Educação Física podem e muito contribuir para esses alunos, pois são nelas que muitas vezes os alunos se expressam mais as suas vontades e desejos.

Já as professoras Maria e Joana acreditam que a importância desses estudantes deficientes com relação à inclusão nas aulas de Educação Física auxilia no aprendizado coletivo com outros estudantes. O ponto principal é a possibilidade dos estudantes se reconhecerem como seres integrantes da sociedade onde vivem e também para a aceitação dos alunos com deficiência com os alunos sem deficiência.

Os educadores da escola percebem o processo de inclusão como algo novo e complexo, numa caminhada continua e que a inclusão não diz respeito apenas em ter presente numa sala de aula do ensino regular uma criança com NEE, mas prestar um atendimento de qualidade (FURINI, 2006, p.3).

A inclusão destes alunos precisam acontecer em todas as ações que são desenvolvidas dentro da escola. Furini (2006, p.4) apresenta que a "inclusão compreende toda a rede de ações, relações, atividades e recursos empregados para o desenvolvimento da inclusão de crianças com Necessidades Educativas Especiais (NEE) no ensino regular".

“A mesma importância como qualquer outro aluno dito 'normal'. Tendo o mesmo objetivo de uma educação de qualidade e igualdades diante da sociedade. Quando o aluno é mencionado como diferente o mesmo 'serve' como mediador de muita aprendizagem como respeito, companheirismo, paciência entre os colegas de sala de aula respeitando a individualidade de cada um durante as aulas teóricas e práticas” (Profa . Maria).

"Para o aluno com deficiência a importância de estar inserido e conviver e realizar atividades junto com os demais para que o mesmo sinta que pode conviver normalmente em todos os meios da sociedade e aceitar-se e lutar pelo seu espaço. Mas não podemos esquecero trabalho individualizado em outro período e assim mais direcionado a sua dificuldade" (Profa. Joana). 
Com relação à aproximação da inclusão com a Educação Física encontramos em nossas análises que os professores precisam e sentem a necessidade de pensar e refletir, cada vez mais sobre a temática discutida. Assim, ao questionarmos os colaboradores sobre a importância da inclusão dos estudantes com deficiência nas aulas de Educação Física, entendemos que este processo é compreendido pelos professores de diferentes formas, as quais se materializam nas falas abaixo:

"Penso que, dependendo do tipo de deficiência, pode ser, ou melhor, é muito benéfica. Porém o profissional deve estar sempre atento e preparar muito bem suas aulas para não 'expor' o aluno de forma que possa constrangê-lo ou impossibilitá-lo de certa forma" (Prof. João).

"O momento das aulas de Educação Física é onde o aluno estando em contato com outras pessoas e podendo realizar junto às atividades, esta podendo perceber a si mesmo e principalmente se sentindo parte do grupo" (Prof. Pedro).

"Penso que mesmo que a escola, família, e colegas ofereçam oportunidades para o mesmo se igualar, o próprio aluno se limita a sua inclusão. Principalmente de alunos no fundamental II, onde a pré-adolescência passa a ser um fator bastante significativo, o mesmo já possa a ter mais vergonha em receber ajuda 'colo' do professor, os colegas já não tem mais a mesma paciência e calma para acompanhá-lo, o mesmo demonstra reconhecer que é limitado a fatores de sua deficiência" (Profa. Maria).

"Para os demais alunos: compreender que todos somos diferentes e temos limitações e assim sermos respeitados como tal, também incentivar que devemos 'cooperar' uns com os outros" (Profa. Joana).

Analisando as respostas dos colaboradores podemos compreender que a importância atribuída a inclusão dos estudantes com necessidades educativas especiais nas aula de Educação Física se dá na maioria das vezes pela própria superação, tanto dos professores como do estudante. Ainda, é perceptível que os professores sentem a necessidade de se prepararem para trabalhar com a inclusão, pois há certa insegurança e medo de expor os alunos a situações indesejáveis, mas entendemos que com o passar do tempo, durante 
suas vivencias e experiências docentes, eles encontram situações difíceis e que a partir dessas situações, refletem e ressignificam suas práticas docentes.

\section{Prática Pedagógica do Professor de Educação Física para dar Conta da Inclusão}

\section{Escolar}

Neste momento, passamos a apresentar as metodologias, encaminhamentos e formas de avaliação que os professores de Educação Física se utilizam em sua prática docente. Percebendo que essa não é uma tarefa fácil, pois os professores, muitas vezes, encontram diversas situações em suas turmas, onde precisam tomar decisões, é importante que essas decisões não favoreçam a exclusão dos alunos, mas sim de que eles deem conta da inclusão dos alunos com deficiência em suas aulas.

Ao questionarmos os professores sobre as estratégias metodológicas utilizadas para encaminhar e ministrar suas aulas, os professores mostram dificuldades em planejar as aulas para que atendas todas as diversidades existentes nas turmas.

“Esta é uma situação realmente complicada. É muito difícil preparar 'todas' as aulas em função de 'um' ou 'dois' alunos, mas sempre que posso tento diversificar para que ninguém seja ou se sinta excluído" (Prof. João).

“Eu procuro conversar com os alunos ditos 'normais' para que tenham paciência e que ajudem o colega a participar das aulas. Isso não vale só para alunos com deficiência, vale também para um aluno que não sabe chutar direito a bola, por exemplo. Se o colega ajudar ao contrario de chamar de 'burro' as aulas se tornam mais atrativas não só para o aluno com deficiência mais para os outros também" (Prof. Pedro).

De acordo com o esboço acima podemos afirmar que o professor também precisa abranger os temas que levem o aluno fora da escola há ter uma continuidade na atividade física, também abranger temas que contribuem para a vida cultural e educacional desse aluno.

[...] o professor bem informado, bem preparado e, principalmente, motivado é um elemento importante para que a Educação Física escolar seja mais interessante ao seu aluno, além de ser um conscientizado para que este, ao ultrapassar as fronteiras da escola, continue praticar uma atividade física, no seu lar, na vizinhança e em outros setores da comunidade (MARTINS JÚNIOR, 2000, p.115). 
A prática pedagógica dos professores de Educação Física com relação à inclusão de alunos com deficiência deve ir além do que está inserido nas escolas. Compreendemos aqui que esses alunos estão inseridos na escola 'regular' para que possa se sentir um ser integrante e acessível na sociedade onde vive, deixando de lado, muitas vezes, o preconceito que muitas pessoas têm com essas crianças, jovens e adultos que são deficientes, seja qual for sua deficiência.

Com relação ainda dos métodos que a professora Maria utiliza em suas aulas para haver a inclusão dos alunos com deficiência ela afirma que:

"Pelo fato da escola ser de porte menor e as turmas serem pequenas, tudo isso facilita o encaminhamento da aula. Da locomoção da sala de aula ate o espaço externo ou ginásio todos vão juntos, sendo o aluno inclusivo recebendo sempre ajuda dos colegas. Chegando ao ambiente a que viemos realizar a aula o mesmo participa desde a conversa inicial, sempre em grande roda até a prática, o qual realiza sem questionar e sempre que adaptado metade da turma faz igual a ele e outra metade faz de forma não adaptada. Em algumas vezes há controvérsias dos alunos 'normais' como é de se considerar, mas com o diálogo e conversa tudo é sempre resolvido" (Profa. Maria).

Para Tardif (2004) tais experiências são adquiridas com o tempo e com a experiência de trabalho. É no dia-a-dia, trabalhando, que se constrói grande parte do conhecimento. Conforme o autor, estes são os saberes experienciais, que no exercício cotidiano de sua função, os condicionamentos aparecem relacionados a situações concretas que não são passíveis de definições acabadas e que exigem improvisação e habilidade pessoal. Constatamos então, que a prática se torna um grande avanço no saber do professor, proporcionando ao docente, autoconfiança em tomar atitudes, devido algumas situações geradas em suas aulas.

Com relação à prática pedagógica dos professores entrevistados, observamos a necessidade de que os planejamentos das aulas estejam fundamentadas em referenciais que contribuam para o desenvolvimento das aulas com estudantes com deficiência. Os professores afirmam ler artigos e demais materiais só que não sabem citar os autores ao qual essa se fundamenta, percebemos na fala do professor João onde ele diz que: 
“[...] Não há autor especifico que eu utilizei apenas pesquisa geral mesmo".

“[...] Eu procuro ler os artigos e tirar dali o embasamento das aulas" (Prof. Pedro).

"Não utilizo nenhum autor especifico para fundamentar as práticas. Apenas materiais adquiridos durante a graduação, cursos semestrais fornecidos pelo sistema de ensino da escola" (Profa. Maria).

"Não sigo nenhum embasamento teórico de autor especifico" (Profa. Joana).

Para Mittler (2003) é durante o percurso profissional que os professores constroem e ampliam suas habilidades, ampliam as experiências que já possuem com o objetivo de alcançar todas as crianças e suas necessidades de aprendizagem. Assim, percebemos a necessidade da formação permanente dos professores, onde estes sentem e precisam buscar conhecimentos para poderem ministrar suas aulas de acordo com as necessidades educacionais dos estudantes. Freire (2002) discute a importância da busca pelo "ser mais", mais reflexivo, mais crítico, mais autônomo. E um dos primeiros passos para isso é se tornar consciente da inconclusão, do professor pesquisador que inicia na formação inicial e se perdura por toda vida docente.

É perceptível nas respostas dos colaboradores que para dar conta da inclusão nas aulas de Educação Física, se preocupam em alguns momentos com o local, material que vão utilizar em suas aulas, para poder, a partir disso incluir os alunos com deficiência, mas ao serem questionados sobre a avaliação destes, percebemos a falta de critérios e entendimento sobre a própria avaliação, pois em alguns casos o critérios utilizado é a participação nas aulas.

"Este critério não é único e pronto. Existem muitas variações e depende muito da proposta pedagógica do trimestre. Outro fator é o grau da deficiência do aluno. Avaliações práticas e teóricas são preparadas de acordo com as possibilidades do aluno" (Prof. João).

"[...] procuro avaliar pela participação nas atividades, ou seja, menos que ele conseguir realizar já vai superando as suas dificuldades [...]" (Prof. Pedro). 
"Quando avalio em conteúdos teóricos o mesmo é avaliado igual aos demais colegas e quando da prática é respeitando suas limitações, participação, interesse, objetividade em estar realizando, não subestimando sua deficiência é muito relevante na avaliação" (Profa . Maria).

"Primeiramente na participação, mas também a evolução psicomotora e outras conforme a dificuldade de cada um" (Profa. Joana).

Alves (2003, p.15) apresenta que a palavra incluir significa "abranger, compreender, envolver, implicar, acrescentar e somar". Dessa forma, todo indivíduo pode ser incluído, pois todos precisam ser envolvidos, implicados, juntados a qualquer outro ser, para somar o crescimento de um ou de outro. Portanto, para os professores fazerem a inclusão acontecer, é preciso que isso seja lembrado desde o momento em que prepara suas aulas até mesmo no modo como as encaminha e como avalia seus alunos.

Entendemos, nessa categoria, que o processo de incluir alunos deficientes nas aulas de Educação Física com relação à prática pedagógica do professor não é uma atividade fácil, há diversas dificuldades a serem superadas por esses docentes, desde a contínua busca pelo conhecimento, a relação com os alunos na sala de aula, planejamentos das atividades, e a própria avaliação. Sentimos a necessidade de uma melhor compreensão do que é o processo de inclusão para esses professores para que pudessem planejar, ministrar e avaliar suas aulas e alunos, principalmente refletir sobre sua prática educativa.

\section{Considerações Transitórias}

Retomando o objetivo deste estudo que é compreender como os professores de Educação Física rede pública e particular organizam a sua prática pedagógica para as turmas com alunos com deficiência incluídos, podemos concluir que a inclusão de fato, ainda não acontece, e que esse é um processo que não pode ficar estaque, é necessário que os professores realizem a contínua busca pelo conhecimento para que possam estar cada vez mais envolvidos com a temática e poder ministrar suas aulas de acordo com as necessidades educativas especiais de cada aluno. Encontramos também a dificuldade dos professores em trabalhar com estudantes com deficiência em suas aulas, pois o professor 
tem que conhecer o processo desse aluno para não realizar atividades que as prejudique em vez de estar colaborando com o seu desenvolvimento e aprendizado.

Com relação à prática pedagógica dos professores participantes, compreendemos que esses têm grandes dificuldades em suas aulas, mas que muitas vezes buscam adaptar suas práticas para que o aluno com deficiência não seja excluído, fazendo com que os outros alunos entendam também o processo ao qual está inserido em uma escola regular.

Percebemos então que para acontecer à inclusão escolar é preciso repensar a ideia de subjetividade dos sujeitos pois esse processo só acontece ao entendemos que cada pessoas possui suas necessidades e diversidades, e ainda que estas aprendem e progridem de formas distintas dentro de seus limites. 


\section{Referências}

ALVES, F. Inclusão: muitos olhares, vários caminhos e um grande desafio. Rio de Janeiro: WAK, 2003.

CARREIRO DA COSTA, F.A.A. Formação de professores: objectivos, conteúdos e estratégias. Revista da Educação Física/UEM, Maringá, v.5, n.1, p.71-81, 1994.

DECLARAÇÃO DE SALAMANCA. Sobre os princípios, políticas e práticas na área das necessidades educacionais especiais. España: Salamanca, 1994.

DORNELES, et. al. Relação teoria e prática da Educação Física no ensino fundamental. Educação Física: prática pedagógica e trabalho docente. UDESC, Florianópolis, v.1, p. 171193, 2012.

FREIRE, P. Pedagogia da autonomia: saberes necessários à prática educativa. 21 . ed. Rio de Janeiro: Paz e Terra, 2002.

FREIRE, P. Pedagogia do Oprimido. 17 ed. Rio de Janeiro: Paz e Terra, 1987.

FURINI, A.B. Processo de inclusão na escola regular: panorama de percepções. Revista Educação Especial, Porto Alegre, v. 28, p.1-5, 2006.

MANTOAN, M.T.E.; PIETO, R.G.; ARANTES, V.A. Inclusão escolar: pontos e contrapontos. 2. ed. São Paulo: Summus, 2006.

MARTINS JUNIOR, J. O professor de Educação Física e a Educação Física Escolar: como motivar o aluno? Revista da Educação Física/UEM, Maringá, v.11, n.1, p.107-117, 2000.

MITTLER, P. Educação inclusiva, contextos sociais. Porto Alegre: Artmed, 2003.

NEGRINE, A. Instrumentos de coleta de informações na pesquisa qualitativa. In: MOLINA NETO, V.; TRIVIÑOS, A.N.S. (Org.). A pesquisa qualitativa na Educação Física: alternativas metodológicas. 2. ed. Porto Alegre: UFRGS/ Sulina, 2004.

NÓVOA, A. Formação de professores e profissão docente. In: NÓVOA, A. (coord.) Os Professores e a Sua Formação. 2.ed. Lisboa: Publicações Dom Quixote, 1995a. p.15-34.

PIMENTA, S.G.; LIMA, M.S.L. Estágio e docência. São Paulo: Cortez, 2004.

SHIGUNOV, V.; SHIGUNOV NETO, A. A formação profissional e a prática pedagógica: ênfase nos profissionais de Educação Física. Londrina: O Autor, 2001. 
TARDIF, M. Saberes docentes e formação profissional. 4. ed. Petrópolis: Vozes, 2004.

VOIVODIC, M.A. Inclusão escolar de crianças com síndrome de down. 3 ed. Petrópolis: Vozes, 2004.

\title{
PRACTICE TEACHING FACULTY OF PHYSICAL EDUCATION FACING THE SCHOOL INCLUSION
}

\begin{abstract}
This study aimed to understand how the pedagogical practice of teachers of Physical Education of the City of Forquilhinha (SC) with students with disabilities included in regular physical education classes in public elementary school classrooms. Participated in the survey two teachers and two teachers of physical education of elementary school, who teach classes at the state school, and particularly. The results showed that less involvement in continuing education in the schools, and the organization of the school inclusion teacher support system is the point that most influences the pedagogical practice of teachers.
\end{abstract}

Keywords: Inclusion. Teacher Training. Teaching practice.

\section{ENSEÑANZA PRÁCTICA DOCENTE DE EDUCACIÓN FÍSICA FRENTE LA INCLUSIÓN DE LA ESCUELA}

RESUMEN: Este estudio tuvo como objetivo comprender como la práctica pedagógica de los profesores de Educación Física de la Ciudad de Forquilhinha (SC) con los alumnos con discapacidad incluida en las clases de educación física en las aulas regulares de la red básica. En la encuesta participaron dos profesores y dos profesores de educación física de la escuela primaria, que enseñan clases en la escuela pública, y en particular la ciudad de Forquilhinha-SC. Los resultados mostraron que una menor participación en la educación continua en las escuelas, y la organización del sistema de ayuda al profesor de la inclusión escolar es el punto que más influye en la práctica pedagógica de los docentes.

Palabras clave: Inclusión y formación del profesorado. práctica docente. 